\title{
SOSIOLEK BAHASA BALI BERDASARKAN VARIABEL USIA DAN ETNIK
}

\author{
I Nyoman Rauh Artana \\ Program Studi Sastra Jepang Fakultas Ilmu Budaya \\ Universitas Udayana \\ rauhartana@gmail.com
}

\begin{abstract}
:
The study of dialectology focuses on language variations based on geographic variables or geographical dialects so that it is known as the study of dialectical geography or linguistic geography but in its development, the study of dialectology extends to language variants based on social variables resulting in social dialectology (Chmabers \& Petyt 1980). The social dialects that arise from the layers of society cause variations in the pronunciation of a sound or word in a language. Bali in particular Denpasar is a small city with a heterogeneous society so that inevitably the contacts of the language of the settlers with native speakers. The occurrence of these influences is related to extralinguistic and linguistic factors (intralinguistik). The linguistic (extralinguistic) situation associated with the person to whom the speaker is speaking, the topic of conversation, and the impulse of the speaker, such as the urge to be parallel / acceptable in the use of language by other speakers of language is the social reason of a person using other language elements. In addition, the factor of readiness or ease of pronunciation of certain language elements is the language factor of a person using other language elements. Ethnic differences result in differences in sound or phonological systems that are adapted to give rise to a dialect. The existence of ethnic Javanese and ethnic Balinese on the island of Bali is characterized by phonological differences that occur in a speech or communication so that withoutintroducing ourselveswealreadyknowtheoriginofthesespeakersfromJava orfromBali.
\end{abstract}

Key words: sociolek, bali language, variable, ethnicity, age

\section{PENDAHULUAN}

Bahasa merupakan salah satu unsur budaya yang hidup dan berkembang dalam masyarakat sebagai pengguna bahasa yang secara lokal mempunyai integritas atau identitas yang menggambarkan ciri dan budaya tersebut melalui bahasa. Sebagai salah satu kebudayaan daerah, bahasa daerah mempunyai tempat yang khusus dan sangat penting diantara produk-produk kebudayaan daerah. Dikatakan penting, karena bahasa daerah selain mengemban fungsi sebagai alat komunikasi antarmasyarakat daerah, bahasa daerah juga berfungsi sebagai media pengembang kebudayaan daerah itu sendiri.

Bahasa Bali, yang untuk seterusnya disingkat
BB, adalah salah satu bahasa daerah yang digunakan sebagai bahasa ibu oleh masyarakat Bali (Bawa, 1984/1985 : 1). BB, sebagai bahasa ibu; adalah bahasa yang pertama kali digunakan oleh komunitas masyarakat Bali sejak mereka dilahirkan dari rahim ibunya. Dengan pengertian ini berarti bahwa penutur BB yang bahasa ibunya BB adalah penutur yang dibesarkan oleh $\mathrm{BB}$, sehingga mayoritas perilaku berbahasanya diselenggarakan dalam BB.

Bahasa Bali sebagai salah satu sub-budaya Bali bukanlah nomenklatur yang mengacu kepada suatu bahasa yang hidup di wilayah pulau Bali, tetapi lebih mengacu kepada Bali sebagai nama etnik (suku bangsa) yaitu suku bangsa Bali. Dengan 
demikian, BB tidak saja hidup di wilayah Pulau Bali namun dapat kita temui di beberapa wilayah seperti pulau Lombok (bagian Barat), di kantongkantong daerah tujuan utama transmigrasi seperti: Sumatra, Kalimantan, Sulawesi, Sumbawa dan Irian.

Pada pengertian yang lebih spesifik, BB sering diacu sebagai bahasa daerah yang hidup di wilayah pulau Bali, karena memang mayoritas orang Bali hidup di Bali. Dalam konteks ini tidaklah berarti bahwasetiap orangyanghidup dipulau Baliotomatis bahasa ibunya adalah BB karena pada kenyataanya banyak kita temukan orang yang berasal dari luar pulau Bali tetapi bisa berkomunikasi dengan BB. Interaksi antara masyarakat yang berasal dari luar Bali dengan masayarakat Bali tidak hanya terbatas dalam urusan ekonomi saja, tetapi meluas sampai pada masalah sosial kemasyarakatan sehinnga terjadi kontak bahasa antara orang Bali dengan masyarakat yang berasal dari luar Bali. Kontak bahasa antara dua etnis yang berbeda ini menghasilkan dialek, yaitu dialek sosial bahasa Bali. Perlu diketahui bahwa unsur fonologi merupakan unsur yang paling dominan sebagai ciri pembeda antara orang yang asli bali berbicara BB dengan yang bukan asli Bali misalnya orang Jawa berbicara BB.

Sebagai alat komunikasi verbal, bahasa dapat dikaji secara internal maupun secara eksternal. Secara internal kajian dilakukan terhadap struktur internal bahasa itu sendiri, mulai dari struktur fonologi, morfologi, sintaksis, sampai struktur wacana. Kajian secara eksternal berkaitan dengan hubungan bahasa itu dengan faktor-faktor atau hal-hal yang ada di luar bahasa, seperti faktor sosial, psikologi, etnis, seni, dan sebagainya. Kajian eksternal bahasa melahirkan disiplin baru yang merupakan kajian antara dua bidang ilmu atau lebih. Salah satunya adalah Dialektologi. Kajian dialektologi terfokus pada pembahasan tentang perbedaan-perbedaan bahasa sebagai manifestasi dari variasi dalam satu bahasa yang sama. Chmabers \& Petyt (1980) mengatakan bahwa kajian dialektologi berfokus pada variasi bahasa berdasarkan variabel geografis atau dialek geografi sehingga dikenal sebagai studi geografi dialek atau geografi linguistik tetapi dalam perkembangannya, kajian dialektologi merambah ke variasai bahasa berdasarkan variabel sosial sehingga terlahir dialektologi sosial (Wolfram, 1974).

Bahasa pada umumnya memiliki variasi yang disebabkan pemakainya. Variasi bahasa menurut pemakainya itu disebut dialek. Sapir (19211949: 147-157) dialek adalah variasi bahasa yang timbul karena latar belakang daerah dan lapisan masyarakat pemakai bahasa tersebut.

Sosiolek atau dialek sosial yang timbul akibat lapisan masyarakat menimbulkan variasi pengucapan suatu bunyi atau kata dalam suatu bahasa. Bali khususnya Denpasar merupakan kota kecil dengan masyarakat yang heterogen sehingga tidak dapat dihindari terjadinya kontakkontak bahasa dari para pendatang dengan penutur asli. Terkait dengan ini, lebih jauh Haugen (1972:327) mengatakan bahwa kehidupan sebuah bahasa di lingkungan bahasa-bahasa lainnya atau ekologi bahasa tidak bisa menghindarkan diri dari terjadinya pengaruh unsur-unsur kebahasaan. Terjadinya pengaruh tersebut berkaitan dengan faktor ekstralinguistik dan faktor kebahasaan (intralinguistik). Situasi kebahasaan (ekstralinguistik) yang terkait dengan orang yang diajak bicara, topik pembicaraan, dan dorongan dari dalam diri pembicara, seperti dorongan untuk sejajar/diterima dalam penggunaan bahasa oleh penutur bahasa lain merupakan alasan sosialkebahasaan seseorang menggunakan unsur bahasa lain. Selain itu, faktor kesiapan atau kemudahan pengucapan unsur bahasa tertentu merupakan faktor kebahasaan seseorang menggunakan unsur bahasa lainnya.

Secara garis besar objek kajian dialektologi dapat dibedakan atas dua bagian besar, yaitu (1) variasi dialektal berdasarkan variabel geografis atau dialek geografi, dan (2) variasi dialektal berdasarkan variabel sosial atau dialeksosial. Variabel geografis adalah daerah-daerah berdeda yang dijadikan titik pengamatan. Sedangkan variabel sosial adalah kelompok-kelompok sosial berbeda berdasarkan kelasa sosial, usia, jenis kelamin pemakai.

Variabel sosial dengan cakupan yang lebih luas yaitu, status, usia, jender, style, dan etnik, 
variabel-variabel sosial ini merupakan pendukung timbulnya suatu dialek.

\section{DATA DAN METODE PENELITIAN}

Metode yang digunakan dalam pengambilan data adalah metode Simak dan Cakap (Mashun, 2005) dengan teknik sadap, teknik sadap dalam hal ini dimaknai sebagai perekaman bahasa dengan menggunakan Speech Analyzer. Data yang dianalisis dalam penelitian ini merupakan hasil dari observasi langsung yang dilakukan di lapangan. Adapun informan yang menjadi narasumber dalam penelitian ini adalah etnik Bali dan etnik Jawa sebagai pendukung dialeksosial BB. Untuk mempersepsikan bunyi supaya mendapatkan data yang akurat, maka pengambilan data dilakukan dengan cara merekam suara informan dengan menggunakan Speech Analyzer kemudian data yang telah terekam diuji validitasnya dengan menggunakan bantuan IPA (International Phonetic Alphabet). Ada 22 data leksikal yang dipakai sebagai instrumen dalam penelitian ini. Selanjutnya dari 22 data yang dianalisis ditemukan bahwa variabel usia tidak memiliki pengaruh terhadap dialek sosial Bali, ini terbukti dari beberapa observasi dan pengamatan yang penulis lakukan tidak ada perbedaan yang signifikan antara usia tua, dewasa, dan muda. Pelafalan bunyi berdasarkan variabel usia relatif seimbang tetapi fakta memperlihatkan bahwa variabel keetnisan lebih dominan mempengaruhi dialek sosial masyarakat Bali.

\section{ISI DAN PEMBAHASAN}

Wolfram (1974: 73) menyebutkan bahwa ada enam variabel sosial untuk dibahas, yaitu: variabel daerah (region), status (status), ragam (style), usia (age), jenis kelamin (seks), dan keetnisan (ethnicity) tetapi pada bagian ini akan dibahas mengenai usia dan etnik sebagai variabel sosial yang menimbulkan terjadinya sosiolek atau dialek sosial. Sebelum penulis memaparkan lebih lanjut masalah usia dan etnik, maka dipandang perlu untuk mengetahui apa itu variabel usia (age) dan keetnisan (ethnicity). Variabel usia terkait dengan umur penutur, umumnya dibedakan atas usia anak-anak, remaja, dewasa, dan tua. Pada umumnya tuturan anak-anak berbeda dengan tuturan orang dewasa ataupun orang tua, hal ini karena perbedaan keperluan dan tingkat pemahaman masing-masing penutur terhadap tuturannya. Orang tua, dewasa, dan muda memiliki gaya dan cara tersendiri untuk membahasakan dirinya. Sedangkan Variabel keetnisan terkait dengan komunitas besar yang heterogen secara etnis, dalam artian ada penduduk asli dan ada penduduk pendatang dari daerah lain, seperti bahasa Bali yang digunakan oleh sekelompok etnik lain yang ada di Bali. Dapat dikatakan bahwa tiap etnik yang berbaur dengan etnik lain telah terlebih dahulu memiliki bahasa daerah sebagai bahasa ibu dan kebiasaan berbahasa pertama terbawa-bawa pada saat menggunakan bahasa kedua atau yang biasa disebut interferensi (penggunaan unsurunsur bahasa pertama pada saat menggunakan bahasa kedua).

Dengan begitu luasnya permasalahan variabel sosial, maka pada penelitian ini ruang lingkup penelitian terfokus pada variabel usia dan etnik yaitu, etnik Bali dan etnik Jawa sebagai penutur bahasa Bali dengan melihat perbedaan-perbedaan yang terjadi dari unsur fonologis.

Data leksikal yang dipakai sebagai instrumen penelitian dapat disimak dalam tabel perbandingan.

Tabel perbandingan variabel usia-keetnisan.

\begin{tabular}{|c|cc|}
\hline \multirow{4}{*}{ USIA } & \multicolumn{2}{|c|}{ ETNIK } \\
\cline { 2 - 3 } & BALI & JAWA \\
\cline { 2 - 3 } & Muda & Dewasa \\
\cline { 2 - 3 } & Muda & Tua \\
\cline { 2 - 3 } & Dewasa & Tua \\
\hline
\end{tabular}

\begin{tabular}{|c|c|c|c|}
\hline \multicolumn{4}{|c|}{ Data Fonologis } \\
\hline No & Penutur Bali & $\begin{array}{l}\text { Penutur } \\
\text { Jawa }\end{array}$ & $\begin{array}{c}\text { Perbedaan } \\
\text { Fonologis }\end{array}$ \\
\hline 1. & $\begin{array}{c}\text { [daar] Bt, } \\
\mathrm{Bd}, \mathrm{Bm}\end{array}$ & $\begin{array}{c}\text { [dahar] Jt, } \\
\mathrm{Jb}, \mathrm{Jm}\end{array}$ & $/ \mathrm{a} / \rightarrow / \mathrm{h} /$ \\
\hline 2. & $\begin{array}{c}\text { [wareg] Bt, } \\
\mathrm{Bd}, \mathrm{Bm}\end{array}$ & $\begin{array}{c}\text { [ware?] Jt, } \\
\mathrm{Jb}, \mathrm{Jm}\end{array}$ & $/ \mathrm{g} /$ \\
\hline 3. & $\begin{array}{c}{[\text { mulih }] \mathrm{Bt}} \\
\mathrm{Bd}, \mathrm{Bm}\end{array}$ & $\underset{\mathrm{Jb}, \mathrm{Jm}}{[\mathrm{mol} \mathrm{i} h]} \mathrm{Jt}$, & $/ \mathrm{u} /$ \\
\hline
\end{tabular}




\begin{tabular}{|c|c|c|c|}
\hline 4. & $\begin{array}{c}{[\text { kenken }] \mathrm{Bt} \text {, }} \\
\mathrm{Bd}, \mathrm{Bm}\end{array}$ & $\mid \begin{array}{c}{[\text { keyken }]} \\
\mathrm{Jb}, \mathrm{Jm}\end{array}$ & $/ \mathrm{n}$ \\
\hline 5. & $\begin{array}{c}\text { [suud] Bt, } \\
\mathrm{Bd}, \mathrm{Bm}\end{array}$ & $\begin{array}{c}\text { [suUut] Jt, } \\
\mathrm{Jb}, \mathrm{Jm}\end{array}$ & $\begin{array}{r}/ \mathrm{u} / \\
\mathrm{w} /\end{array}$ \\
\hline 6. & $\begin{array}{c}\text { [ragane] Bt, } \\
\mathrm{Bd}, \mathrm{Bm}\end{array}$ & $\underset{\mathrm{Jb}, \mathrm{Jm}}{[\text { ragané] }} \mathrm{Jt}$ & \\
\hline 7. & $\begin{array}{c}\text { [subeng] Bt, } \\
\mathrm{Bd}, \mathrm{Bm}\end{array}$ & \begin{tabular}{|c|}
{$\left[\begin{array}{c}\text { sobeng] } \\
\mathrm{Jb}, \mathrm{Jm}\end{array}\right.$} \\
\end{tabular} & \\
\hline 8. & $\begin{array}{c}\text { [kuping] } \mathrm{Bt} \text {, } \\
\mathrm{Bd}, \mathrm{Bm}\end{array}$ & $\underset{\mathrm{Jb}, \mathrm{Jm}}{[\text { koping] }} \mathrm{Jt}$ & \\
\hline 9. & $\begin{array}{c}\text { [mayah] Bt, } \\
\mathrm{Bd}, \mathrm{Bm}\end{array}$ & $\underset{\mathrm{Jb}, \mathrm{Jm}}{[\mathrm{mayah}]} \mathrm{Jt}$, & \\
\hline 10. & $\begin{array}{c}\text { [jegeg] Bt, } \\
\mathrm{Bd}, \mathrm{Bm}\end{array}$ & $\begin{array}{c}\text { [jegél] Jt, } \\
\mathrm{Jb}, \mathrm{Jm}\end{array}$ & \\
\hline 11. & $\begin{array}{c}\text { [dueg] Bt, } \\
\text { Bd, Bm }\end{array}$ & $\begin{array}{l}\text { [due |] Jt, } \\
\mathrm{Jb}, \mathrm{Jm}\end{array}$ & ' \\
\hline 12. & $\begin{array}{c}\text { [ngih] Bt, } \\
\text { Bd, Bm }\end{array}$ & $\begin{array}{c}\text { [ygih] Jt, } \\
\mathrm{Jb}, \mathrm{Jm}\end{array}$ & \\
\hline 13. & $\begin{array}{c}{[\text { tumben] Bt, }} \\
\mathrm{Bd}, \mathrm{Bm}\end{array}$ & $\begin{array}{l}\text { [tombén] } \\
\mathrm{Jt}, \mathrm{Jb}, \mathrm{Jm}\end{array}$ & $/ \mathrm{u} / \rightarrow$ \\
\hline 14. & $\begin{array}{c}\text { [lebihan] Bt, } \\
\mathrm{Bd}, \mathrm{Bm}\end{array}$ & $\begin{array}{c}{[\text { lebean] } \mathrm{Jt},} \\
\mathrm{Jb}, \mathrm{Jm}\end{array}$ & 1 \\
\hline 15. & \begin{tabular}{|c} 
[melaib] Bt, \\
$\mathrm{Bd}, \mathrm{Bm}$
\end{tabular} & \begin{tabular}{|c|}
{$[$ melaeb] Jt, } \\
$\mathrm{Jb}, \mathrm{Jm}$
\end{tabular} & \\
\hline 16. & $\begin{array}{c}\text { [mandus] } \\
\mathrm{Bt}, \mathrm{Bd}, \mathrm{Bm}\end{array}$ & $\begin{array}{l}\text { [mand,us] } \\
\mathrm{Jt}, \mathrm{Jb}, \mathrm{Jm}\end{array}$ & $/ \mathrm{d} / \rightarrow$ \\
\hline 17. & $\begin{array}{c}\text { [apa]/[apə] } \\
\mathrm{Bt}, \mathrm{Bd}, \mathrm{Bm}\end{array}$ & $\underset{\mathrm{Jm}}{[\mathrm{ap} \partial]_{\mathrm{Jt}}, \mathrm{Jb},}$ & $1 \rightarrow 1$ \\
\hline 18. & $\begin{array}{c}{[\mathrm{kija}] /[\mathrm{kij} \partial]} \\
\mathrm{Bt}, \mathrm{Bd}, \mathrm{Bm}\end{array}$ & $\begin{array}{l}\text { [kijo] Jt, } \\
\mathrm{Jb}, \mathrm{Jm}\end{array}$ & \\
\hline 19. & $\begin{array}{c}\text { [bajang] Bt, } \\
\mathrm{Bd}, \mathrm{Bm}\end{array}$ & $\underset{\mathrm{Jb}, \mathrm{Jm}}{[\mathrm{Baja} \eta]} \mathrm{Jt}$ & $\begin{array}{l}/ \mathrm{b} / \rightarrow / \mathrm{B} /, \\
/ \mathrm{ng} / \rightarrow / \mathrm{n} /\end{array}$ \\
\hline 20. & $\begin{array}{l}{[\mathrm{aba}] /[\mathrm{abs}]} \\
\mathrm{Bt}, \mathrm{Bd}, \mathrm{Bm}\end{array}$ & $\underset{\mathrm{Jm}}{[\mathrm{ab} J]} \mathrm{Jt}, \mathrm{Jb}$, & $/ \mathrm{g} / \rightarrow / \mathrm{o} /$ \\
\hline 21. & $\begin{array}{c}\text { [numbeg] } \\
\mathrm{Bt}, \mathrm{Bd}, \mathrm{Bm}\end{array}$ & $\begin{array}{l}\text { [numbe?] } \\
\mathrm{Jt}, \mathrm{Jb}, \mathrm{Jm} \\
\end{array}$ & $/ \mathrm{g} / \rightarrow / ? /$ \\
\hline 22. & $\begin{array}{c}\text { [rame] Bt, } \\
\mathrm{Bd}, \mathrm{Bm}\end{array}$ & $\begin{array}{c}\text { [ramé] Jt, } \\
\mathrm{Jb}, \mathrm{Jm}\end{array}$ & $/ \mathrm{e} / \rightarrow / \mathrm{e} /$ \\
\hline
\end{tabular}
Keterangan:
Bt : Bali Tua
Jm : Jawa Muda
Bd : Bali Dewasa
BB : Bahasa Bali
Bm: Bali Muda
PB : Penutur Bali
Jt : Jawa Tua
PJ : Penutur Jawa
Jd : Jawa Dewasa
$\rightarrow$ : Menjadi

\section{Analisis}

Analisis data dilakukan dengan cara membandigkan data yang diperoleh dari informan kemudian data tersebut diolah dengan melihat perbedaan fonologis dalam melafalkan kata-kata bahasa Bali oleh penutur Bali (PB) dan penutur Jawa (PJ).

Berdasarkan data dalam tabel di atas, ditemukan ada beberapa perbedaan fonologis yang menyebabkan munculnya dialek sosial BB, seperti yang terlihat pada data, yaitu; bunyi /a/ vokal pusat tengah menjadi glotal frikative $/ \mathrm{h} / ; / \mathrm{g} /$ menjadi glotal plosive /?/; seperti pada daar (PB) dan dahar (PJ) 'makan'; wareg (PB) dan ware? $\div$ (BJ). Bunyi /g/ (BB) yang berdistribusi di akhir kata pada umumnya diadaptasi ke bunyi /?/ atau bisa juga ke bunyi /k/ oleh (PJ). Kemudian vokal tengah tak bundar /O/ (PB) pada umumnya menjadi vokal belakang tengah bundar / / / PJ). Perubahan /i/ yang tinggi-depan menjadi /e/ yang sedang-depan, seperti pada kata lebihan dan melaib dilafalkan oleh (PB) tetapi menjadi lebehan dan melaeb dilafalkan oleh (PJ). Perubahan tersebut menandakan bahwa sistem alat ucap penutur (PJ) cenderung menggunakan cara pengucapan perendahan/ lebih rendah daripada cara pengucapan BB. Bunyi /ng/ lafal (BB) diadaptasi menjadi

/y/ nasal velar oleh (PJ); bunyi /d/ (BB) diadaptasi menjadi bunyi /t/ oleh (PJ); /i/ tinggi depan mengalami perendahan menjadi /i/ pusat rendah.

Secara keseluruhan perbedaan fonologis, tampak terjadinya perubahan bunyi perendahan, yaitu dari bunyi /i/ menjadi /e/ dan dari bunyi /u/ menjadi bunyi /o/ secara konsisten. Perubahan bunyi seperti itu bukan karena lingkungan bunyi terdekat (pengaruh bunyi terdekat), tetapi karena motivasi kebiasaan alat ucap (artikulatoris) bahwa 
penutur Jawa cenderung mengucapkan bunyi yang lebih rendah atau lebih lemah sehingga ketika penutur Jawa berbahasa Bali, maka dengan mudah dapat kita ketahui bahwa orang yang sedang berbicara BB itu bukanlah etnis Bali tetapi etnis Jawa yang sedang berbicara BB. Dialek.

\section{SIMPULAN}

Ulasan sederhana yang telah dideskripsikan di atas merupakan gambaran sederhana yang sangat terbatas, baik mengenai ruang lingkup pembahasannya maupun sumber dan contoh datanya sehingga hasil yang diperoleh juga sangat terbatas. Peneliti mencoba mengungkapkan hanya sebagian kecil dari permasalahan yang berkaitan dengan dialek sosial bahasa Bali dimana pendukungnya adalah penutur Bali asli dan penutur Jawa. Terkait dengan itu, untuk mendapat hasil yang maksimal diperlukan kajian yang lebih luas dan mendalam.

Sebagai akhir pembahasan hasil penelitian ini perlu disimpulkan sebagaimana diuraikan berikut ini. Setelah melalui proses analisis data, pengolahan dan pembahasannya, hasil penelitian ini dapat disimpulkan bahwa dari dua variabel sosial yang dijadikan tolok ukur dalam penelitian ini yaitu variabel usia dan variabel etnik, mendapatkann temuan sebagai berikut: 1) variabel usia tidak menunjukkan pengaruh yang signifikan terhadap variasi bahasa Bali (dialek Bali); 2) variabel usia relatif seimbang dalam melafalkan pola bunyi, artinya baik usia muda, dewasa, dan tua tidak menunjukkan perbedaan yang mencolok sehingga peneliti berasumsi bahwa variabel usia tidak memenuhi standar untuk diteliti lebih lanjut; 3) ditemukan bahwa variabel keetnisan memiliki pengaruh yang sangat dominan terhadap dialek sosial bahasa Bali. Perbedaan etnis menimbulkan adanya perbedaan sistem bunyi atau fonologis yang di adaptasi sehingga memunculkan sebuah dialek. Keberadaan etnis Jawa dan etnis Bali di pulau Bali dicirikan oleh perbedaan fonologis yang terjadi dalam suatu tuturan atau komunikasi sehingga tanpa memperkenalkan diri pun kita sudah tahu asal pembicara tersebut dari Jawa atau dari Bali. Suatu ciri dialek adalah bahwa para penutur dari dialek-dialek bahasa yang sama masih saling mengerti (mutual intelligibility) dan kalau dialek-dialek ini tidak saling dimengerti oleh para penuturnya, maka dialek-dialek ini menjadi bahasa yang mandiri. 